Proc. Indian Acad. Sci. (Chem. Sci.), Vol. 102, No. 5, October 1990, pp. 693-696.

(C) Printed in India.

\title{
Raman spectroscopic study of the environment of tryptophan residues in bovine $\alpha$-lactalbumin
}

\author{
H VAN DAEL*, E TIEGHEM and F VAN CAUWELAERT \\ Interdisciplinair Research Centrum, K.U. Leuven Campus Kortrijk, B-8500 Kortrijk, \\ Belgium

\begin{abstract}
Lactalbumin is an important protein essential for lactose synthesis. The conformation, position and state of different amino acid side chains and the structural changes in environment are important parameters which afiect the functional properties. In this paper, the use of Raman bands for the study of the environment of tryptophan residues is presented and discussed.
\end{abstract}

Keywords Raman spectra; environment of Trp residues; bovine $\alpha$-lactalbumin.

\section{Introduction}

$\alpha$-Lactalbumin is a small globular protein that acts as a specifier protein essential for lactose synthesis. It is a calcium metalloprotein that possesses an additional binding site for $\mathrm{Zn}^{2+}$ ions. Although the stabilizing role of the $\mathrm{Ca}^{2+}$ binding was observed by different techniques, the precise effects on the conformation and its impact on the biological processes are still unclear. Besides peptide backbone conformation, the position and the state of the different amino acid side chains are very important physical parameters in the study of the structure and the function of a protein. After our investigation on the tyrosine Raman doublet in $\alpha$-lactalbumin (Van Dael et al 1987), we examine in this work the tryptophan residues and their dependence on specific environmental and structural factors. As pointed out recently by Miura et al (1988), two Raman bands (around $880 \mathrm{~cm}^{1-}$ and $1360 \mathrm{~cm}^{1-}$ ) have been found useful in the study of the Trp environment.

\section{Results}

\subsection{The Trp band at $880 \mathrm{~cm}^{-1}$}

According to normal coordinate analysis, the $880 \mathrm{~cm}^{-1}$ band is a mixed mode of the benzene 12-like vibration and $\mathrm{N}_{1} \mathrm{H}$ motion. The frequency of this band reflects the strength of the H-bonding at the NH site of the indole ring of Trp (Miura et al 1988). The lower the frequency, the stronger is the $\mathrm{H}$-bonding. Within the precision of our experiments $\left( \pm 1 \mathrm{~cm}^{-1}\right)$, no obvious shift of the $880 \mathrm{~cm}^{-1}$ band could be detected

* For correspondence 
upon the addition of $\mathrm{Ca}^{2+}$ to the apo-form of $\alpha$-lactalbumin. The H-bonding at the $\mathrm{NH}$ site is therefore not noticeably affected by the Ca content.

Recently a calcium-induced conformational change was reported (Heremans and Heremans 1988) by observing the intensity ratio of the $880 \mathrm{~cm}^{-1}$ band versus the $1450 \mathrm{~cm}^{-1}$ band of the $\mathrm{CH}_{2}$-scissoring mode. Regarding our results obtained on various samples at different temperatures, we doubt that the intensity ratio $h_{880} / h_{1450}$ is a good parameter to monitor the $\mathrm{Ca}^{2+}$ influence. The spread of the data depending on sample preparation and temperature makes it difficult to relate this intensity ratio to the $\mathrm{Ca}^{2+}$ content in an unambiguous way.

\subsection{The $1360-1340 \mathrm{~cm}^{-1}$ Trp doublet}

The intensity of the $1360 \mathrm{~cm}^{-1}$ band is mostly interpreted as a contribution of buried Trp residues and indole rings accessible to the solvent are not expected to contribute to that feature (Yu 1974). Miura et al (1988) however speculate that the intensity of the $1360 \mathrm{~cm}^{-1}$ band is more generally a marker of the hydrophobicity of the environment. Not only buried Trp but also exposed Trp on the molecular surface but surrounded by aliphatic side chains could contribute to this band intensity.

Two methods were used to calculate the relative intensity of the two peaks in the Trp doublet. In the first method (used in figure 1) the peak height of each peak is determined against the adjacent minimum in the protein spectrum at $1375 \mathrm{~cm}^{-1}$. The second method (used in figure 2) takes an extrapolation of a linear baseline from $1375 \mathrm{~cm}^{-1}$ to $1480 \mathrm{~cm}^{-1}$ as reference. Both these methods give comparable results (table 1).

At low temperature $\left(6^{\circ} \mathrm{C}\right)$ where the protein is folded, the Trp environment is not changed by $\mathrm{Ca}^{2+}$ addition. Only when the molar ratio $>1$, a small increase in hydrophobicity of the environment is observed. At higher temperatures $\left(21-31^{\circ} \mathrm{C}\right)$, $R$ remains unchanged for the samples with molar ratio 0.8 and $1 \cdot 2$. For these samples the thermal unfolding has not yet started and the hydrophobic Trp environment is still intact.

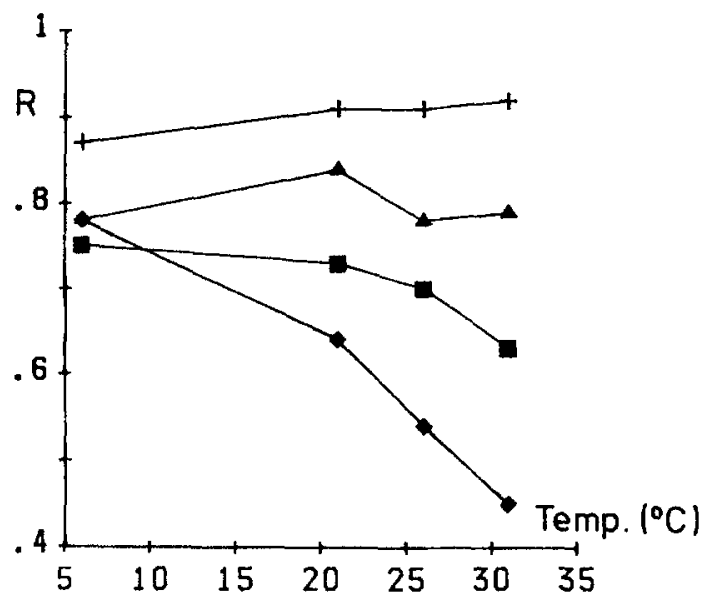

Figure 1. Temperature dependence of $R=h_{1360} / h_{1340}$ in bovine $\alpha$-lactalbumin without $\mathrm{Ca}^{2+}(\bullet)$, with $\mathrm{Ca}^{2+}$ molar ratios $0.4(\mathrm{a}), 0.8(\Delta)$ and $1.2(+)$. 


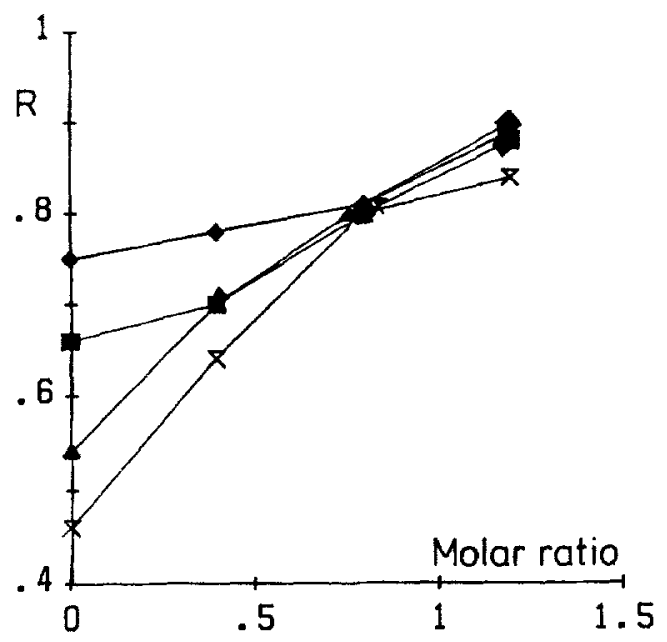

Figure 2. Calcium content dependence of the $\operatorname{Trp}$ doublet in bovine $\alpha$-lactalbumin at $T=6(\bullet), 21(\square), 26(\Delta)$ and $31^{\circ} \mathrm{C}(\bar{x})$.

Table 1. $R=h_{1360} / h_{1340}$ as a function of $\mathrm{Ca}^{2+}$ content (molar ratio) at different temperatures. The results obtained by both methods of peak height determination are given.

\begin{tabular}{lcccc}
\hline & \multicolumn{4}{c}{ Temperature $\left({ }^{\circ} \mathrm{C}\right)$} \\
\cline { 2 - 5 } $\begin{array}{c}\text { Molar } \\
\text { ratio }\end{array}$ & 6 & 21 & 26 & 31 \\
\hline Apo & 0.78 & 0.64 & 0.54 & 0.45 \\
& 0.75 & 0.66 & 0.54 & 0.46 \\
0.4 & 0.75 & 0.73 & 0.70 & 0.63 \\
& 0.78 & 0.70 & 0.70 & 0.64 \\
0.8 & 0.78 & 0.84 & 0.78 & 0.79 \\
& 0.81 & 0.80 & 0.81 & 0.80 \\
1.2 & 0.87 & 0.91 & 0.91 & 0.92 \\
& 0.89 & 0.88 & 0.90 & 0.84 \\
\hline
\end{tabular}

The $0.4 \mathrm{Ca}$ and the apo sample on the other hand progressively unfold (figures 1 and 2). In this process, Trp is transferred to a more hydrophilic environment.

\section{Conclusion}

Instead of the intensity of the $880 \mathrm{~cm}^{-1}$ band, the Trp doublet at $1340-1360 \mathrm{~cm}^{-1}$ can be used as an internal probe for $\mathrm{Ca}$-induced conformational change. Our experiments clearly șhow an increase of the $1360 \mathrm{~cm}^{-1}$ band intensity as a function of $\mathrm{Ca}^{2+}$ concentration. The occupation of the $\mathrm{Ca}^{2+}$ site thus triggers a conformational reorganization whereby the mean hydrophobicity of the Trp environment has increased. 


\section{References}

Heremans L and Heremans K 1988 Proceedings of the XIth ICORS (London: J Wiley)

Miura T, Takeuchi H and Harada 11988 Biochemistry 2788

Van Dael H, Lafaut J P and Van Cauwelaert F 1987 Eur. Biophys. J. 14409

Yu N T $1974 \mathrm{~J}$. Am. Chem. Soc. 964664 